\title{
Primary care referral protocol for wrist ganglia
}

\author{
F D Burke, E Y Melikyan, M J Bradley, J J Dias
}

Postgrad Med J 2003;79:329-331

The paper summarises current knowledge on ganglia of the wrist including the views of patients and doctors. The efficacy of available treatment options are discussed. Summary points are derived from the available knowledge with a referral protocol from primary care.
See end of article for authors' affiliations

Correspondence to: Professor F D Burke, Pulvertaft Hand Centre, London Road, Derby, DE 1 2QY UK

frank.burke@virgin.net

Submitted

22 November 2002

Accepted

12 February 2003

\section{INCIDENCE OF GANGLIONS}

Ganglia are the commonest swellings around the wrist. The incidence is high with referrals to a local hand unit from primary care rising in the last decade from 44 per 100000 of population to 55 per 100000 of population per year

\section{PATHOGENESIS}

The cause of ganglions remains uncertain but the volar wrist swelling originates from the radioscaphoid or scaphotrapezial joints. ${ }^{1}$ Only a small minority give a history of previous trauma. ${ }^{2}$ Small "daughter" cysts have been noted in the normal scapholunate ligament at the time of dorsal ganglion excision. These may be the source of the fluid that tracks through the joint capsule to form a collection in the more superficial layers. The capsule of the ganglion is formed by compressed stroma without a cellular lining. This may be linked to the joint by a narrow channel which can act as a one way valve. ${ }^{3}$

\section{NATURAL HISTORY}

Most ganglia present in females ${ }^{4}$ in the second, third, or fourth decades of life. ${ }^{5}$ Spontaneous resolution is common with $50 \%$ of untreated patients "ganglion free" when assessed at six years.

\section{DIFFERENTIAL DIAGNOSIS}

Ganglions are site specific overlying the scapholunate ligament on the dorsum of the wrist and over the radiocarpal or scaphotrapezial joints on the volar surface adjacent to the radial artery. Transillumination will confirm that there is clear fluid in the ganglion unless it is very deep, small, or the patient is dark skinned.

Rheumatoid extensor tenosynovitis may have a similar appearance to a dorsal ganglion, but there are usually subtle clinical clues to differentiate between the two. Extensor tenosynovitis may not transilluminate as well as a ganglion. Maximal digital extension will usually demonstrate the "tuck" sign (a puckering of the swelling at its distal end) confirming the synovial origin of the tissue. A radial artery aneurysm may mimic a volar ganglion but may be identified by expansile pulsations.

\section{PATIENTS' PERCEPTION}

Westbrook et al analysed the views of 50 patients attending a hand clinic with a diagnosis of ganglion. ${ }^{6}$ Twenty eight percent were concerned about possible malignancy and 38\% attended for cosmetic reasons; $26 \%$ had sought help because of pain. Ganglions (along with carpal tunnel syndrome) have been noted to be one to the conditions most frequently associated with a failure to attend the new patient hand clinics. ${ }^{7}$

\section{GENERAL PRACTITIONERS' PERCEPTION}

All Southern Derbyshire Health Authority general practitioners (GPs) were sent a questionnaire by the Pulvertaft Hand Centre inquiring into primary care attitudes and management of several common hand conditions, including ganglia. A total of 179 out of 320 questionnaires were returned for analysis (a 56\% response rate for practitioners, and $77 \%$ practice response). Over $90 \%$ of GPs considered ganglia were fairly easy to diagnose. Nevertheless $71 \%$ felt a referral protocol from primary care would be helpful (see box 1). They shared a common view with surgeons in secondary care that most patients with ganglia do not require operative intervention. Only $7 \%$ felt ganglia required treatment frequently $(70 \%$ occasionally and $22 \%$ rarely); $63 \%$ would not treat a ganglion in primary care. The minority of GPs who did treat ganglions in primary care favoured aspiration $(22 \%)$, with a smaller number injecting steroid (12\%). It seems about half the GPs employ reassurance when dealing with patients with ganglia, although most would not consider this a form of treatment. GPs have a realistic view on surgical outcome (56\% frequently satisfactory and $38 \%$ sometimes satisfactory).

\section{TREATMENT OPTIONS}

\section{Reassurance alone}

The Trent regional audit of ganglions indicated that $33 \%$ of dorsal ganglions and $45 \%$ of volar wrist ganglia will resolve spontaneously in six years. The Derby ganglion audit reviewed the progress of 729 ganglions up to 10 years from attendance. The authors confirmed a spontaneous resolution in untreated cases of $63 \%$ for volar ganglia and $51 \%$ for dorsal ganglia. Reassurance alone avoids therapeutic complications and can reasonably be employed for many patients attending with ganglia.

\section{Aspiration alone}

Nield and Evans found a 59\% recurrence at one year after wide bore aspiration alone. ${ }^{8}$ The Derby audit confirms a recurrence rate of $67 \%$ when dorsal ganglia are treated with this technique (with an $88 \%$ recurrence rate for volar ganglia). Richman et al noted a 63\% recurrence rate with 
Box 1: Referral letter from GPs referring patients with wrist ganglia

I have assessed my patient using the Derby Ganglion Referral Protocol and wish to refer the patient because:

All boxes in section A should be ticked, along with the relevant boxes in section $B$.

\section{Section A}

1. $\square$ The ganglion transilluminates.

2. $\square$ The patient is aware that most ganglia resolve spontaneously with the passage of time.

3. $\square$ The patient is aware of the complications of ganglion excision $30 \%$ recurrence and $15 \%$ scar tenderness or numbness. Persistent wrist stiffness may also occur).

\section{Section B}

1. $\square$ The patient's ganglion is painful and restricts work and hobbies.

2. $\square$ The patient remains concerned by the risk of malignancy, despite aspiration and reassurance.

3. $\square$ The patient has failed to respond to aspiration of the ganglion.

4. $\square$ The ganglion is ugly.

5. $\square$ Other reasons; please specify:

aspiration and multiple wall puncture. ${ }^{9}$ Zubowicz and Ishii favour repeated aspiration of up to three aspirations and found that the technique resolved $85 \%$ of ganglia in their series. ${ }^{10}$ Oni reduced the need for surgery by this technique to $12 \%$ of referrals. ${ }^{1}$

Westbrook et al see an additional benefit to aspiration. The technique offers strong reassurance to the $28 \%$ of patients presenting through fear of malignancy thereby reducing the need for this group to consider surgical excision. ${ }^{6}$ Aspiration of ganglion fluid, and showing the patient the contents of the ganglion, is an additional reinforcement to the reassurance already given. Stephen et al confirm this view, noting that only $18 \%$ of referred cases requested surgical excision after aspiration had been employed.

\section{Aspiration with steroid injection}

Varley et al observed a similar recurrence rate for aspiration alone and aspiration with steroid injection $(67 \%) \cdot{ }^{13}$ Lower recurrence rates $(40 \%)$ are noted by Holm and Pandey, ${ }^{14}$ but Wright et al recorded a recurrence rate of $80 \%$ with no additional gains from a repeat aspiration injection. ${ }^{15}$ The Derby audit noted a recurrence rate of $54 \%$ in 13 volar ganglia and $42 \%$ in 45 dorsal ganglia when treated by this technique. Both rates are lower than with aspiration alone but the sample sizes are very small. Paul and Sochart report on a lower recurrence rate if hyaluronidase is also used.$^{16}$ The recurrence rate was $11 \%$ if hyaluronidase was used $(43 \%$ with aspiration and steroid alone).

\section{Ganglion excision}

Angelides quotes a $1 \%$ recurrence rate and Clay and Clement offer a 3\% recurrence rate, but most series offer considerably higher figures. ${ }^{17}$ Faithful and Seeto record a $14 \%$ recurrence rate for wrist ganglia. ${ }^{18}$ Dias and Buch report a $27 \%$ recurrence rate in 370 dorsal ganglions with a $40 \%$ recurrence rate in 230 volar ganglions. ${ }^{19}$ The Derby audit reveals a $28 \%$ recurrence rate in 262 dorsal ganglia with a $25 \%$ recurrence rate in 166 volar ganglia. There are additional complications beyond recurrence. Persistent scar tenderness or sensitivity is noted in $15 \%$ of Dias' series particularly in volar ganglia excision. Jacobs and Govaers observed 28\% recurrence in this group with the same percentage complaining of pain, dysaesthesia, or numbness in the area of the scar or the palmar cutaneous branch of the median nerve. ${ }^{20}$

\section{Summary points}

- Adult dorsal and volar wrist ganglions are site specific and can usually be diagnosed with confidence in primary care by clinical examination and transillumination.

- Patients consult their doctors for three main reasons: pain, cosmesis, or fear of malignancy.

- Reassurance should be considered the first therapeutic intervention.

- If there is an underlying fear of malignancy this may well be overcome by reassurance combined with aspiration of the ganglion contents, showing the patients the fluid content from the swelling

- Aspiration with steroid injection does not seem to offer a lower recurrence to aspiration alone.

- There are significant complications after ganglion surgery (notably recurrence in a quarter to a third of cases), joint stiffness, scar sensitivity, or distal numbness.

- If a patient is referred from primary care after aspiration they should be aware that they are being referred for consideration of surgical excision and be aware of the potential complications as described above.

- Occult ganglia are an important cause of chronic wrist pain. Ultrasound is effective in identifying such ganglions.

- Ganglions in children have a particularly high spontaneous resolution rate.

- The indications for operative intervention are therefore more limited.

\section{Arthroscopic dorsal ganglia excision}

Povlsen and Peckett treated patients with painful ganglia arthroscopically and identified carpal abnormalities frequently. ${ }^{21}$ Underlying carpal abnormality should always be considered when assessing painful wrist ganglia for surgical excision. Pain may be arising from the wrist joint, rather than the ganglion, and pain relief after ganglion excision should not be assumed. A $25 \%$ recurrence rate was observed by Ho et al. ${ }^{22}$ Single figure recurrence rates are offered by Osterman (Singh and Culp, 2002), ${ }^{23}$ Luchetti et al, ${ }^{24}$ and Nishikawa et al ${ }^{25}$ in fairly small case series. Shih et al report no recurrences at a mean 26 month review in a 32 patient series. ${ }^{26}$

\section{Surgery for recurrent ganglions}

Only a minority of patients chose to go forward with recurrent ganglion surgery. The Derby audit reveals the risk of recurrence after re-excision at 19\% for 16 recurrent volar ganglia and 14\% for 22 recurrent dorsal ganglia.

\section{OCCULT DORSAL WRIST GANGLIA}

Poorly localised pain to the dorsum of the wrist in the area of the scapholunate ligament may indicate a small occult ganglion. ${ }^{27}$ Ultrasound is an effective way of demonstrating the ganglia when it is too small to palpate. ${ }^{28}$ The condition is an important differential diagnosis in the assessment of dorsal wrist pain of unknown aetiology. ${ }^{29}$

\section{GANGLIONS IN CHILDREN}

A high spontaneous resolution rate of $63 \%$ is reported by MacCollum ${ }^{30}$ with higher rates $(76 \%)$ by Rosson and Walker. ${ }^{31}$ Wang and Hutchinson report a 79\% spontaneous resolution rate. ${ }^{32}$ For this reason reassurance (rather than surgery) is recommended by the authors.

\section{Authors' affiliations \\ F D Burke, E Y Melikyan, M J Bradley, J J Dias, Pulvertaft Hand Centre, Derby}

\section{REFERENCES}

1 Shapiro PS, Seitz WH. Non-neoplastic tumours of the hand and upper extremity. Hand Clinics 1995;11:133-60. 
2 Angelides AC, Wallace PF. The dorsal ganglion of the wrist, its pathogenesis gross and microscopic anatomy and surgical treatment. $J$ Hand Surg [Am]1976:1:228-35.

3 Angelides AC. Ganglions of the hand and wrist. In: Green DP, ed. Operative hand surgery. 2nd Ed. New York: Churchill Livingstone, 1998: 2281-99.

4 Barnes WE, Larson RD, Posch JL. Review of ganglia of the hand and wrist with analysis of surgical treatment. Plast Reconstr Surg 1964;34:570-8

5 Minotti P, Taras JS. Ganglion cysts of the wrist. Journal of American Society for Surgery of the Hand 2002;2:102-7.

6 Westbrook AP, Stephen AB, Oni J, et al. Ganglia: the patients perception. J Hand Surg $[\mathrm{Br}]$ 2000;25:566-7.

7 Bradley MJ. Study to investigate the causes of non attendance at hand surgery out-patient clinic for a new patient appointment. Derby: University of Derby, 1999 (MSc thesis).

8 Nield DV, Evans DM. Aspiration of ganglia. J Hand Surg $[\mathrm{Br}]$ 1986;11:264

9 Richman JA, Gelberman RH, Engber WD, et al. Ganglions of the wrist and digits. Results of treatment by aspiration and cyst wall puncture. J Hand Surg [Am] 1987;12:1041-3.

10 Zubowicz VN, Ishii CH. Management of ganglion cysts of the hand by simple aspiration. J Hand Surg [Am] 1987;12:618-20.

11 Oni J. Treatment of ganglia by aspiration alone. J Hand Surg $[\mathrm{Br}]$ 1992;17:660.

12 Stephen AB, Lyons AR, Davis TRC. A prospective study of two conservative treatments for ganglia of the wrist. J Hand Surg $[\mathrm{Br}]$ 1999;24:104-5.

13 Varley GW, Needoff $M$, Davis TRC, et al. Conservative management of wrist ganglia. J Hand Surg $[\mathrm{Br}]$ 1997;22:636-7

$14 \mathrm{Holm}$ PCA, Pandey SD. Treatment of ganglia of the hand and wrist with aspiration and injection of hydrocortisone. The Hand 1973;5:63-7. 5 Wright TW, Cooney WP, Ilstrup DM. Anterior wrist ganglion. J Hand Surg [Am] 1984;19:954-8.

16 Paul AS, Sochart DH. Improving the results of ganglion aspiration by the use of hyalurondase. J Hand Surg [Br] 1997;22:219-21.

17 Clay NR, Clement DA. The treatment of dorsal wrist ganglia by radical incision. J Hand Surg $[\mathrm{Br}] 1988 ; 13: 187-91$.
18 Faithful DK, Seeto BG. The simple wrist ganglion-more than a minor surgical procedure. Hand Surgery 2000;5:139-43.

19 Dias JJ, Buch K. Palmar wrist ganglion: does intervention improve outcome. A prospective study of the natural history and patient reported treatment outcomes. J Hand Surg [Br] 2003;28:172-6.

20 Jacobs LGH, Govaers KJM. The volar wrist ganglion-just a simple cyst? $J$ Hand Surg $[\mathrm{Br}]$ 1990;15:342-6.

21 Povlsen B, Peckett WR. Arthroscopic findings in patients with painful wrist ganglia. Scand J Plast Reconstructive Surg 2001;35:323-8.

22 Ho PC, Griffiths J, Lo WN, et al. Current treatment of ganglion of the wrist. Hand Surgery $2001 ; 6: 49-58$

23 Singh D, Culp RW. Arthroscopic ganglionectomy. Journal of the American Society for Surgery of the Hand 2002;2:33-8.

24 Luchetti R, Badia A, Alfarano M, et al. Arthroscopic excision of dorsal wrist ganglia and treatment of recurrences. J Hand Surg $[B r]$ 2000;25:38-40.

25 Nishikawa S, Toh S, Miura H, et al. Arthroscopic diagnosis and treatment of dorsal wrist ganglia. J Hand Surg [Br] 2001;26:547-9.

26 Shih JT, Hung ST, Lee HM, et al. Dorsal ganglion of the wrist: results of treatment by arthroscopic resection. J Hand Surg [Asean] 2002;27: 1-5.

27 Steinberg BD, Kleinman WB. Occult scapholunate ganglion-a cause of dorsal radial wrist pain. J Hand Surg [Am] 1999;24:225-31.

28 Osterwalder JJ, Widrig R, Stober R, et al. Diagnostic validity of ultrasound in patients with persistent wrist pain and suspected occult ganglion. J Hand Surg [Am] 1997;22:1034-40.

29 Vo P, Wright T, Hayden F, et al. Evaluating dorsal wrist pain: MRI diagnosis of occult dorsal wrist ganglion. J Hand Surg [Am] 1995;20:667-70.

30 MacCollum MS. Dorsal wrist ganglions in children. J Hand Surg [Am] 1997;22:235.

31 Rosson JW, Walker G. The natural history of ganglia in children. J Bone Joint Surg Br 1989;71:707-8.

32 Wang AA, Hutchinson DT. Longtitudinal observation of pediatric hand and wrist ganglia. J Hand Surg [Am] 2001;26:599-602.

\title{
BMJ
}

\section{3rd Asia Pacific Forum on Quality Improvement in Health Care} 3-5 September 2003, Auckland, New Zealand

We are delighted to announce this forthcoming conference in Auckland, New Zealand.

The themes of the 3rd Asia Pacific Forum on Quality Improvement in Health Care are:

- Agenda for quality: Improving equity in health care delivery

- Improving safety

- Leadership for improvement

- Measuring quality and benchmarking for change

- Evidence based knowledge and education for quality improvement

- Improving health systems

- Patient/consumer centred quality improvement

Presented to you by the BM Publishing Group (London, UK) and Institute for Healthcare Improvement (Boston, USA), supported by the New Zealand Ministry of Health, ACC, and Standards New Zealand.

For more information about the Forum or to register contact: quality@bma.org.uk or go to:

\author{
www.quality.bmipg.com
}

Tel: +44(0)2073836409 Fax: +44(0)2073836869 